NOTICE: this is the author's version of a work that was accepted for publication in Patient Education and Counselling. Changes resulting from the publishing process, such as peer review, editing, corrections, structural formatting, and other quality control mechanisms may not be reflected in this document. Changes may have been made to this work since it was submitted for publication. A definitive version was subsequently published in Patient Education and Counselling, 83, 3, 2011 DOI 10.1016/j.pec.2011.04.027 


\section{Diabetes Medication Assistance Service: The Pharmacist's Role in Supporting Patient Self-Management of Type 2 Diabetes (T2DM) in Australia}

Bernadette Mitchell ${ }^{a}$, Carol Armour ${ }^{a}$, Mary Lee ${ }^{a}$, Yun Ju Song ${ }^{a}$, Kay Stewart ${ }^{b}$, Greg Peterson ${ }^{c}$, Jeff Hughes ${ }^{\mathrm{d}}$, Lorraine Smith ${ }^{\mathrm{a}}$, Ines Krass ${ }^{\mathrm{a} \text { * }}$

${ }^{a}$ Faculty of Pharmacy, University of Sydney, New South Wales, Australia

${ }^{\mathrm{b}}$ Faculty of Pharmacy and Pharmaceutical Sciences, Monash University, Victoria, Australia

${ }^{\mathrm{C}}$ Tasmanian School of Pharmacy, University of Tasmania, Tasmania, Australia

${ }^{\mathrm{d} S}$ School of Pharmacy, Curtin University, Western Australia, Australia

*Corresponding Author: Ines Krass, Faculty of Pharmacy, The University of Sydney, Camperdown, New South Wales, Australia 2006. Email: ines.krass@sydney.edu.au

\section{ABSTRACT}

Objective: To evaluate the capacity and effectiveness of trained community pharmacists in delivering the Diabetes Medication Assistance Service (DMAS) via (1) number and types of self-management support interventions (SMSIs); (2) number of goals set and attained by patients and (3) patient outcomes (glycaemic control, medication adherence and satisfaction). Methods: Pharmacists $(n=109)$ from 90 community pharmacies in Australia were trained and credentialed to deliver the DMAS. The training focused on developing pharmacists' knowledge and skills in supporting patients' diabetes self-management.

Results: A total of 387 patients completed the trial. The mean number of SMSIs per patient was 35 (SD \pm 31$)$ and the majority (87\%) had at least one documented goal that were fully or partially attained. There were significant health benefits for patients including improved glycaemic control and a reduced risk of non-adherence to medications. Over $90 \%$ of DMAS patients reported improvements in their knowledge about diabetes self-management. Conclusion:

This study demonstrates the effectiveness of community pharmacists in delivering SMSIs to patients with T2DM.

Practice implication: Given appropriate training in diabetes care and behavior change strategies, community pharmacists can offer programs which provide self-management support to their patients with T2DM and improve their health outcomes.

Keywords: Patient education, diabetes self-management, goal setting, pharmacist, evaluation 


\section{Introduction}

Worldwide, type 2 diabetes mellitus (T2DM) has been described as a major epidemic which imposes a huge cost burden on families, communities and health care systems. In Australia, according to recent national estimates, $7.2 \%$ of the population have T2DM [1], half of whom have not yet been diagnosed [2]. The prevalence is expected to escalate in line with the continuing rise of risk factors that contribute to the development of T2DM. There is now conclusive evidence that intensive glycaemic control can reduce the risk and delay the onset of complications, and therefore improve the overall quality of life for people with T2DM [3-7]. However, the achievement of strict glycaemic control is highly dependent on the extent to which an individual is able to self-manage their condition. Successful self-management of T2DM requires individuals to engage in various cognitive and behavioural processes on a daily basis to maintain blood glucose levels within the normal range, including lifestyle modifications, adherence to medications, self-monitoring of blood glucose (SMBG) and regular visits to health care professionals (HCPs). For many people with T2DM, selfmanagement is challenging as they do not possess adequate knowledge, skills and motivation to initiate and maintain behavioural changes to help them control their illness [810].

A critical strategy to address this is to educate HCPs to empower patients to be proactive in the self-management of their condition. The use of motivational interviewing and collaborative goal setting to facilitate self-management support interventions (SMSIs) delivered by HCPs, has been shown to improve health outcomes for a range of chronic diseases including T2DM [11-15]. Motivational interviewing is a patient centered counseling approach designed to enhance the patient's intrinsic motivation for behavior change [16]. It is based on exploring patient beliefs about perceived difficulties in changing their behavior. The collaborative goal setting technique involves the negotiation and setting of small, achievable and specific goals by patients with the assistance of their HCP to address their most pressing problems. Each goal is supported by a strategy designed to help the patient achieve those goals. The attainment of behaviour change is optimized through the patient's personal investment in this process.

The positive effects of goal setting in changing behaviour may be explained by the selfefficacy theory [17] which suggests that successful goal attainment enhances self-efficacy by 
motivating the patient to set and pursue future goals [18] and increases resilience when faced with barriers in goal pursuit [19]. The goal setting technique has been recognised by the American Diabetes Association to be a key component of diabetes self-management education programs [20].

Community pharmacies provide easily accessible HCPs for ongoing self-management support of chronic conditions such as asthma [21] and T2DM [22]. However, the training of pharmacists in behaviour change strategies and evaluation of their application in patients with T2DM has not been previously reported. A recent trial, the Diabetes Pilot Program, funded by the Australian Government Department of Health and Ageing as part of the Fourth Community Pharmacy Agreement, involved the development of a training program to prepare pharmacists to deliver the Diabetes Medication Assistance Service (DMAS), a care cycle of assessment, counseling, education and review for people with T2DM, provided at regular intervals at the pharmacy over a 6 month period.

The aim of this study was to evaluate (1) the impact of pharmacist training on the process of service delivery via the number and types of self-management support interventions (SMSIs) delivered by the DMAS pharmacists; (2) the impact of DMAS on patient self-management behaviours via the number and types of goals set and subsequently attained by patients and; (3) the impact of the DMAS on patients' outcomes including mean blood glucose levels, medication adherence and patient satisfaction with the service. 


\section{Methods}

\subsection{Ethics approval}

Approval for this study was granted from the Human Research Ethics Committees at The University of Sydney, New South Wales (NSW), Curtin University, Western Australia (WA), Monash University, Victoria (VIC) and The University of Tasmania, Tasmania (TAS).

\subsection{Recruitment of pharmacies}

The recruitment of 90 community pharmacies took place during November and December 2007. The pharmacy eligibility criteria included having a:

- Credentialed DMAS pharmacist

- Process to allow an uninterrupted DMAS consultation

- Screened counseling area or separate counseling room

\subsection{Training and credentialing of the pharmacists}

Participating pharmacists were required to complete a $\mathbf{2}$ day competency-based, face to face, training workshop on delivery of the DMAS. The first day of the workshop focused on developing the pharmacists' diabetes specific skills, use of insulin pens, blood glucose testing devices, interpretation of SMBG and the application of motivational interviewing and collaborative goal setting. The second day involved an overview of patient education strategies and familiarization of participants with the study protocol and documentation. Experts in each of these areas were recruited by the project team and presented a mix of lectures and skills workshops to achieve the desired competency. Prior to the workshop, pharmacists were required to read a manual which introduced the topics of pathophysiology, diagnosis, complications, comorbidities and pharmacotherapy of type 2 diabetes. The information in the manual was assumed baseline knowledge for the 2 day training workshop. 
One hundred and nine pharmacists from 90 pharmacies in metropolitan and rural locations across Australia (NSW, VIC, TAS, WA and Australian Capital Territory) were trained and credentialed to deliver the DMAS during January and February 2008. The workshops comprised a mix of lectures, skills sessions, case discussions and role plays. On completion, participants were asked to complete an evaluation questionnaire to identify participants' perceptions of the training workshops. The credentialing was based on a three component examination; 1) a 10 item MCQ test of diabetes knowledge, 2) a test of competence in using a blood glucose meter and downloading software, 3) three short answer case scenarios requiring interpretation of blood glucose readings. This examination was conducted independently by representatives from the Australian Association of Consultant Pharmacy (AACP), the professional accrediting body. Participants who failed any component of the assessment had the opportunity to resit the test.

\subsection{Patient recruitment and baseline assessment}

Each pharmacy was asked to recruit up to 10 patients and eligible patients were those with T2DM who had an $\mathrm{HbA}_{1 \mathrm{c}}>7.0$, confirmed by their GP. On their first DMAS visit, patients were given a MediSense Optium Xceed ${ }^{\mathrm{TM}}$ blood glucose meter, instructed on its use, and then asked to take measurements at least once daily (preferably at different times). During this visit, the pharmacist recorded each patient's demographic details, diabetes history and current management, height, weight, smoking status, level of physical activity and medication adherence.

\subsection{Pharmacist delivery of the DMAS Intervention}

During the next 4 DMAS visits, the pharmacists used the Precision Link Direct Device $^{\mathrm{TM}}$ to download each patient's blood glucose readings taken in the period since their last visit to generate printouts and charts of their blood glucose results which formed the basis of discussions between the pharmacist and the patient on areas of inadequate glycaemic control. The pharmacists then delivered appropriate SMSIs based on the pharmacist's 
assessment, taking into consideration their blood glucose readings as well as any specific concerns the patient had about their T2DM. A SMSI was any action taken by a pharmacist during the consultation to address issues relating to SMBG, medication adherence, medication problems or lifestyle such as exercise, diet, foot care. Goals to be achieved by the next visit were negotiated with the patient and documented on a worksheet. At the final visit, the patient completed the final medication adherence assessment and a patient satisfaction questionnaire. A separate patient file was used by the pharmacist to document service delivery including clinical data, and SMSIs and patients goals throughout the DMAS. All patients' files were collected at the end of the study and the data entered into an SPSS data base.

\subsection{Evaluation of processes and outcomes}

The impact of DMAS was evaluated on a wide range of process and outcome measures (Table 1). The Brief Medication Questionnaire (BMQ) [23] is an instrument designed to be administered by a health professional to assess medication taking behavior and barriers to adherence. It consists of three scores (screens): a regimen screen, belief screen, and recall screen. In all screens, a higher score indicates a higher risk of non-adherence. Patient satisfaction at the end of the DMAS was measured with the DDSMQ, a validated questionnaire of 21 items based on a 5 point Likert scale scored from 1 (strongly disagree) through to 5 (strongly agree). It comprises 3 subscales "service", "knowledge" and "self-management" [24].

\subsection{Patient qualitative interviews}

To further investigate patient experiences with DMAS, interviews were conducted by telephone with a random sample, stratified by state, of 100 patients who had attended all 5 DMAS visits. The semi structured interviews, conducted by researchers, explored six core issues including overall experience, patient understanding of DMAS, patient expectations; pharmacists' delivery of the service; perceived need for an ongoing DMAS and willingness to pay. 


\subsection{Data analyses}

The data were analysed using SPSS 15.0 TM. Descriptive statistics were used to characterise the DMAS population in terms of demographics, diabetes history, clinical characteristics, frequency of the types of SMSIs and goals set, and the proportion of goals attained. To test for changes in clinical parameters over time, within each group, either paired Student's $t$ tests or Wilcoxon signed ranks test for continuous variables or the McNemar's test for categorical variables were used. The level of significance for all tests was set at $p<0.05$.

The patient interviews were tape recorded with permission, transcribed verbatim and thematically analysed. 


\section{Results}

\subsection{Training evaluation}

Overall the training workshop was well rated by participants (Table 2) who expressed enthusiasm for their involvement in the DMAS and appreciated the importance of the credentialing for the credibility of the role. Participants reported feeling confident in being able to implement the DMAS in their pharmacies (median rating 2 [IQR 1-3]).

\subsection{Recruitment and completion of DMAS patients}

Seven pharmacies withdrew prior to recruitment. The remainder (83 pharmacies) recruited patients between March and June 2008. A total of 998 patients agreed to participate but of these 474 were ineligible, i.e., without a recent $\mathrm{HbA}_{1 \mathrm{c}}>7$. Therefore, 524 patients were enrolled into the program (i.e., a mean of 6 [range 1-10] per pharmacy). A total of 387 patients (74\%), (i.e., a mean of 5 [range 1-10] per pharmacy), completed all 5 DMAS visits. The main reasons for patient withdrawal were patient relocation (6\%), patient losing interest (5\%) and pharmacist issues (7\%). Pharmacist issues included pharmacist illness, employee pharmacist relocation and maternity leave.

\subsection{Patient demographics and diabetes history at baseline}

The mean age for the entire cohort was 63 years with similar proportions of males and females (Table 3). On average, patients had had diabetes for 10 years with the most commonly self-reported diabetes co-morbidities being high blood pressure and high cholesterol (Table 3). At baseline, the majority of patients reported being treated with oral hypoglycaemic medications only (Table 4). 
3.4. Self-management support interventions (SMSI) delivered by the pharmacists

A total of 18,144 SMSIs were delivered by the pharmacists to patients during the DMAS consultations. The mean number of SMSIs per patient was 35 (SD \pm 31$)$. DMAS patients received SMSIs relating to medication adherence (83\%), medication use problems (51\%), SMBG (80\%) and lifestyle (77\%) (Figure 1). SMSIs relating to medication adherence included education about medications, ability to access medications and insulin administration and were received by $83 \%, 55 \%$ and $47 \%$ of patients, respectively. SMSIs relating to medication use problems included drug or dose discrepancies, potential therapeutic problems, and "other" problems and were received by $46 \%, 42 \%$ and $44 \%$ of patients, respectively. SMSIs relating to SMBG included technique, hypoglycaemia and hyperglycaemia and were received by $80 \%, 65 \%$ and $72 \%$ of patients, respectively. Lifestyle SMSIs included physical activity and nutrition advice being received by more than $70 \%$ of patients; smoking and alcohol SMSIs by $37 \%$ of patients; and foot care SMSIs by $65 \%$ of patients.

\subsection{Total number of documented goals}

The records for completed patients $(n=387)$ were further evaluated to establish the number and types of goals set and attained. Of these, 347 (90\%) had at least one documented goal in the patient file. The most common type of goal was physical activity (26\%). This was followed by diet (23\%), SMBG (15\%) and the "other" category (8\%) which comprised foot care, insulin dosage adjustment, blood pressure control and complications monitoring. One-third of the goals were attained while a greater proportion of goals were partially attained (53\%). In contrast, only $14 \%$ of goals were not attained to any degree.

\subsection{Baseline and final measures of the DMAS intervention}

There was a significant reduction in the mean blood glucose levels (BGL) of patients from $9.5( \pm 4.4) \mathrm{mmol} / \mathrm{L}$ to $8.7( \pm 2.1) \mathrm{mmol} / \mathrm{L}$ over the 6 months of the DMAS $(\mathrm{t}=3.5 ; \mathrm{df}$ $385 ; p<0.001)$. The proportion of $B G L$ readings outside range fell from $59 \%( \pm 26 \%)$ to $52 \%( \pm 26 \%)(t=4.8 ; d f 385 ; p<0.001)$. In the BMQ adherence screens, patients showed a 
significant reduction in mean regimen, belief and total screen scores indicating a reduction in the risk of non-adherence to medication (Table 5). In terms of individual items making up the BMQ screens, there were reductions in the proportion of patients who reported stopping or interrupting therapy due to a late refill (from $9.7 \%$ to $7.5 \%$ ); taking less than the prescribed amount (from $13.3 \%$ to $10.0 \%$ ); taking more than the prescribed amount (from $3 \%$ to $1.4 \%$ ); or missing doses (from $22.4 \%$ to $18.7 \%$ ). The proportion of patients who smoked decreased and, in addition, there was an increase in the proportion of patients who exercised three or more times per week, but these improvements were not statistically significant. There was no significant change in the proportion of patients exercising more than five times per week nor was there any change in BMI.

\subsection{Patient satisfaction}

A total of 323 patients completed the DDSM-Q at the end of the DMAS and the results showed that patients were highly satisfied with the "service" perspective of DMAS, which was centered on the delivery of the service by the pharmacist. The results of the sub-scales relating to patient satisfaction on "knowledge" and "self-management" of their diabetes are shown in Tables 6 and 7, respectively. Almost all respondents agreed with the statements "I am satisfied with my understanding of when I should check my blood sugar levels" and that "the service gave me confidence to deal with my diabetes".

\subsection{Patient Interviews}

A number of distinct themes were identified. The majority of patients reported improvements in monitoring of their diabetes, medication adherence, lifestyle management and understanding of diabetes and its complications. Patients who were newly diagnosed with diabetes reported that they gained a lot of knowledge from the DMAS. In contrast, patients who had had diabetes for a number of years reported that while the DMAS did not necessarily increase their knowledge on diabetes, it increased their motivation to improve the management of their diabetes, especially lifestyle and medication issues supported by SMBG. 


\subsubsection{Impact on knowledge of SMBG}

Patients reported that improved SMBG supported by the printouts and discussions during the DMAS visit increased their awareness about their blood glucose levels.

"Monitoring twice a day... my blood test came down to 8 - 9 from 12 - 13." (Patient 16, NSW)

"Loved the charts as I could see myself improving each time." (Patient 4, WA)

\subsubsection{Impact on knowledge of medications}

In general patients reported improvements in understanding of diabetes medications and those on insulin therapy were better able to manage insulin dosing using the SMGB results.

"I learned that I was taking my medications incorrectly...should have been taking them before meals and I had been taking them after meals." (Patient 16, NSW) "Working out the balance between insulin and food intake .......and alter the units as needed. I tend to get hypos between midnight and 1am so need to control insulin amount in evenings." (Patient 2, WA)

\subsubsection{Impact on knowledge of lifestyle}

Patients reported that the pharmacist educated them about appropriate diet, exercise, alcohol and smoking and advised how improvements in lifestyle management played an important role in improving glycaemic control. In many cases, pharmacists referred patients to a dietician and the patient brought the dietician's report to subsequent DMAS visits for discussion with the pharmacist.

"It was fantastic because I had no control over my diabetes. I lost weight (14 kilos)." (Patient 17, NSW)

"I have cut down on the number of cigarettes I smoke every day and only drink once a week now. More exercise and less cigarettes." (Patient 12, NSW)

"I learnt a hell of a lot..... I have a better understanding of the effects of alcohol and exercise on my blood sugars." (Patient 18, NSW) 


\section{Discussion}

\subsection{Discussion}

The DMAS training workshops were well received by the pharmacists who expressed confidence in engaging their patients in diabetes self-management support and education. Importantly, pharmacists reported that the training workshops had enabled them to apply their diabetes knowledge and skills during the DMAS trial.

Most patients received SMSIs from the DMAS pharmacists relating to medication adherence, SMBG and lifestyle while 50\% received SMSIs relating to medication use problems. The high frequency of SMSIs per patient over the 6 months DMAS reflects the complexity of diabetes self-management which involves adherence to diet, physical activity, medication and SMBG. A single visit would not allow for adequate coverage of all aspects of self-management relevant to the individual and highlights the need for repeated contacts with HCPs in the process of chronic care [25].

The importance of review and monitoring of goals to support behavior change by patients was also underscored by the need to reset goals that had only been partially met at follow up visits which suggests that behavior change takes time. Goal setting is a process whereby the patient is often required to learn and master an entirely new cognitive skill (ie. problem identification, setting attainable and realistic goals), while at the same time to develop mastery over changing entrenched habits. In particular, lifestyle factors such as losing weight or giving up smoking are not achievable within a short time-frame. To maintain patients' motivation for behavior change and maximize the likelihood of successfully attaining these goals, external sources of regular support and positive reinforcement from health professionals is critical [26-28].

The patient processes evaluated during the DMAS showed that most patients had a least one documented goal and the most common of these related to lifestyle or SMBG. There were very few goals set in relation to medications which may indicate a lack of patient "readiness" to set a specific goal that is relevant to them about their medications. The greater willingness of patients to set goals around lifestyle indicates that when patients are given choice in self-management of their chronic condition they are likely to focus on those aspects 
of self-management which are of most personal importance or relevance to them [21, 29]. The essence of successful goal attainment is personal investment and the degree of perceived controllability an individual has over an event [28, 30,31]. In the context of the current study, lifestyle changes may be viewed as more personally controllable than changes to medication regimens.

At the end of the DMAS, achievement of goals was reflected in the improved patient health outcomes. This indicates that the pharmacists could provide effective SMSIs to foster lifestyle changes to achieve glycaemic control and reduce the risk of complications [32]. Furthermore, the level of goals which were attained suggests that the necessary skills, knowledge and motivation to drive behavior change strategies were acquired by patients during the DMAS.

Approximately one third of this patient cohort at baseline had not received any prior diabetes education. The reasons for this were not recorded but the willingness of these patients to participate in a community pharmacy diabetes education program may suggest a lack of other education programs for T2DM in the local area, or an increased convenience/accessibility of attending an education program at their local pharmacy. This was highlighted by the high level of patient satisfaction with the pharmacists' delivery of the DMAS as well as the environment and convenience of the pharmacy. There was strong support for continued availability of the DMAS in their local community pharmacy.

After the trial, a majority of DMAS patients reported having increased knowledge and motivation with respect to diabetes self-management. This was reflected in significant improvements in medication adherence scores and a significant reduction in mean blood glucose levels during the DMAS. The clinical effectiveness of the DMAS has been reported previously and included significant reductions in $\mathrm{HbA}_{1 \mathrm{c}}$, blood pressure, total cholesterol and triglycerides [22]. Patients reported that they liked the pie charts and graphs printed by the pharmacist during the visits. The patient often brought a copy to a subsequent visit to the GP or specialist. The effectiveness of community based SMSIs delivered by trained HCPS immediately prior to a visit to the GP has been shown to empower patients to take a more pro-active approach in their interactions with their GP [33]. Patients who were newly diagnosed found the DMAS extremely useful as they had no previous understanding of diabetes or its complications. These individuals reported very significant improvements in lifestyle which is typically recommended for those newly diagnosed with T2DM [32]. 
Furthermore, patients who were on insulin improved their ability to monitor and make adjustments to their insulin dose in response to blood glucose readings and changes in physical activity and food intake.

There were some limitations to this study. Firstly it did not include a control group, so we cannot be certain that the changes in outcomes were due to the pharmacist intervention alone. However the DMAS was previously tested in an RCT and shown to be clinically effective [22]. Much of the data, including adherence, goal setting and pharmacist interventions, were self-reported and therefore, may be subject to bias. To address this limitation, further improvements to the patient file documentation would be required in the future to optimize the recording of goal setting and pharmacist SMSIs.

\subsection{Conclusion}

Community pharmacies are a valuable and underutilized resource for the disease management of T2DM. The results of this study suggest that appropriately trained pharmacists can deliver effective self-management support to patients with T2DM in the community setting. The most useful component of the DMAS was the pharmacists' support of SMBG as a tool to help the patient effectively self-manage aspects of their diabetes, including food intake, exercise and correct medication use. Other benefits of DMAS included improved understanding of diabetes and its management and increased motivation to lose weight and exercise regularly. The DMAS service resulted in improved clinical outcomes and was highly valued by patients, based both on the findings of the interviews and the patients' satisfaction questionnaires. Given that the DMAS was implemented in 83 pharmacies of differing sizes located in $\mathbf{5}$ states across Australia in rural and metropolitan communities suggests that the model may be generalisable.

\subsection{Practice Implications}

This study supports the feasibility and effectiveness of community pharmacists in supporting self-management behaviors of patients with T2DM. Based on evidence from large clinical trials [22], the extent of improvement in diabetes control achieved by the DMAS will translate into future cost savings to the health care system in delaying and reducing diabetes related complications. 


\section{Acknowledgements}

This project was funded by the Australian Commonwealth Department of Health and Ageing under the Fourth Community Pharmacy Agreement. We would like to thank Kitty Yu, Tonie Miller and Sajni Gudka for collection and entry of data as well as the study participants for their significant contribution to the trial. 


\section{References}

[1] Diabetes prevalence in Australia: an assessment of national estimates (2009). Australian Institute of Health and Welfare. Canberra, Australian Capital Territory. http://www.aihw.gov.au/publications/cvd/cvd-46-10639/cvd-46-10639.pdf

[2] Diabesity and associated disorders in Australia 2000. The Final Report of the Australian Diabetes, Obesity and Lifestyle Study (AusDiab). International Diabetes Institute. http://www.diabetes.com.au/pdf/AusDiab Report.pdf

[3] Blood glucose control in type 2 diabetes. Australian Centre for Diabetes Strategies, Prince of Wales Hospital. National Health and Medical Research Council (2009) http://www.nhmrc.gov.au/ files nhmrc/file/publications/synopses/di9.pdf

[4] Prevention and detection of macrovascular disease in type 2 diabetes. Australian Centre for Diabetes Strategies, Prince of Wales Hospital. National Health and Medical Research Council (2009) http://www.nhmrc.gov.au/ files nhmrc/file/publications/synopses/di11.pdf

[5] Patel A, MacMahon S, Chalmer J. Intensive blood glucose control and vascular outcomes in patient with type 2 diabetes. N Engl J Med 2008;358:2560-72.

[6] Duckworth W, Abraira C, Moritz T. Glucose control and vascular complications in veterans with type 2 diabetes. N Engl J Med 2009;360:129-39.

[7] Stratton I, Alder A, Neil H. Association of glycaemia with macrovascular and microvascular complications of type 2 diabetes (UKPDS 35): prospective observational study. Brit Med J 2000;321:405-12.

[8] Glasgow RE, Toobert DJ, Hampson SE, Strycker LA. Implementation, generalization, and long-term results of the "choosing well" diabetes self-management intervention. Patient Educ Couns 2002;48:115-22. 
[9] Harris S, Petrella R, Leadbetter W. Lifestyle interventions for type 2 diabetes: relevance for clinical practice. Can Fam Physician 2003;49:1618-25.

[10] Thoolen B, de Ridder D, Bensing J, Gorter K, Rutten G. Beyond good intentions: the development and evaluation of a proactive self-management course for patients recently diagnosed with type 2 diabetes. Health Educ Res 2008;23:53-61.

[11] Barlow JH, Sturt J, Hearnshaw H. Self-management interventions for people with chronic conditions in primary care: examples from arthritis, asthma and diabetes. Health Educ J 2002;61:365-78.

[12] DeWalt DA, Davis TC, Wallace AS, Seligman HK, Bryant-Shilliday B, Arnold CL, Freburger J, Schillinger D. Goal setting in diabetes self-management: taking the baby steps to success. Patient Educ Couns 2009;77:218-23.

[13] Brand CA, The role of self-management in designing care for people with osteoarthritis of the hip and knee. Med J Australia 2008;189:S25-S28.

[14] Zwar N, Harris M, Griffiths R, Roland M, Dennis S, Powell Davies G, Hasan I. A systematic review of chronic disease management. Australian Primary Health Care Research Institute (2006) http://www.anu.edu.au/aphcri/Domain/ChronicDiseaseMgmt/Approved 3 Zwar.pdf

[15] Cooper HC, Booth K, and Gill G. Patients' perspectives on diabetes health care education. Health Educ Res 2003;18:191-206.

[16] Handley M, MacGregor K, Schillinger D, Sharifi C, Wong S, Bodenheimer T. Using action plans to help primary care patients adopt healthy behaviours: A descriptive study. J Am Board Fam Med 2006;19:224-31.

[17] Bandura A. Self-efficacy: the exercise of control. 1997; New York: W.H Freeman. 
[18] Marks R, Allegrante J, Lorig K. A review and synthesis of research evidence for selfefficacy enhancing intervention for reducing chronic disability: implications for health education practice (part 1). Health Promot Pract 2005;6:37-43.

[19] Schwarzer R, Luszczynska A, Ziegelmann JP, Scholz U, Lippke S. Social-cognitive predictors of physical exercise adherence: three longitudinal studies in rehabilitation. J Health Psychol 2008;27:S54-63.

[20] Education Recognition Programs. American Diabetes Association. http://professional.diabetes.org/recognition. aspx?cid=57995

[21] Smith L, Bosnic-Anticevich S, Mitchell B, Saini B, Krass I, Armour A. Treating asthma with a self-management model of illness behaviour in an Australian community pharmacy setting. Soc Sci Med 2007;64:1501-11.

[22] Krass I, Armour C, Mitchell B, Brillant M, Dienaar R, Hughes J, Lau P, Peterson G, Stewart K, Taylor S, Wilkinson J. The Pharmacy Diabetes Care Program: assessment of a community pharmacy diabetes service model in Australia. Diabetic Med 2007;24:677-83.

[23] Svarstad BL, Chewning BA, Sleath BL, Claesson C. The Brief Medication Questionnaire: a tool for screening patient adherence and barriers to adherence. Patient Educ Couns 1999;37:113-24.

[24] Krass I, Delaney C, Glaubitz S, Kanjanarach T. Measuring patient satisfaction with diabetes disease state management services in community pharmacy. Res Soc Adm Pharm 2009;5:31-9.

[25] Rothman AA, Wagner EH. Chronic illness management: what is the role of primary care? Ann Intern Med 2003;138:256-61. 
[26] Battersby MW, Ask A, Reece MM, Markwick M, Collins JP. The Partners in Health scale: the development and psychometric properties of a generic assessment scale for chronic condition self-management. Aust J Prim Health 2004;9:41-52.

[27] Sheldon K, Williams G, Joiner T. Self-determination theory in the clinic: motivating physical and mental health. 2003; Yale University Press: New Haven.

[28] Zimmerman B. Attaining self-regulation. In: Boekaerts M, Pintrich P, Zeidner M, editors. Handbook of self-regulation. San Diego: Academic Press, 2000;13-15.

[29] Williams G, Freedman Z, Deci D. Supporting autonomy to motivate patients with diabetes for glucose control. Diabetes Care 1998;21:1644-50.

[30] Bandura A. The primacy of self-regulation in health promotion. Appl Psychol-Int Rev $2005 ; 54: 245-54$

[31] Deci EL, Ryan RM. The 'what' and 'why' of persuit goals: human need and the selfdetermination of behaviour. Psychol Inq 2000;11:227-68.

[32] National evidence based guidelines for the management of type 2 diabetes mellitus. National Health and Medical Research Council (2005) http://www.nhmrc.gov.au/publications/synopses/di7todi13syn.htm.

[33] Deen D, Wei-Hsin L, Rothstein D, Santana L, Gold MR. Asking questions: The effect of a brief intervention in community health centers on patient activation. Patient Educ Couns 2010; In Press. 
Table 1: Process and Outcome Measures

Process Number of self-management support interventions

(SMSIs) delivered by the pharmacists

Number of goals set by the patients

Number of goals attained by the patients

Outcome Mean blood glucose levels at each DMAS visit

Medication adherence (BMQ)

Body mass index (BMI)

Physical activity

Smoking status

Patient satisfaction (DDSM-Q) 
Table 2: Pharmacists' evaluation of the

DMAS training workshop $(n=109)$

Criterion

Median

(IQR)

Expectation of the workshop

2

("1" very well to "7" very poor)

Relevance of the workshop

("1" relevant to "7" irrelevant)

Amount of information

("1" too much to "7" too little)

Lectures

("1" excellent to "7" poor)

Skills session

("1" excellent to "7" poor)

Goal setting 3

("1" excellent to "7" poor)

Cases

("1" excellent to "7" poor)

IQR: Interquartile range 
Table 3: Demographic characteristics of DMAS patients at baseline $(n=524)$

\begin{tabular}{|c|c|c|c|}
\hline \multirow{2}{*}{\multicolumn{2}{|c|}{ Age (years) }} & \multirow{2}{*}{$\begin{array}{r}\text { Mean } \\
62.8 \\
\end{array}$} & \multirow{3}{*}{$\begin{array}{c}S D \\
11.1 \\
\%\end{array}$} \\
\hline & & & \\
\hline & & $N$ & \\
\hline \multicolumn{4}{|l|}{ Gender } \\
\hline & Male & 278 & 53 \\
\hline & Female & 243 & 46 \\
\hline & Missing & 3 & 1 \\
\hline \multicolumn{4}{|l|}{ Country of birth } \\
\hline & Australia & 353 & 67 \\
\hline & Other & 163 & 31 \\
\hline & Missing & 8 & 2 \\
\hline \multicolumn{4}{|l|}{ Reside } \\
\hline & Alone & 109 & 21 \\
\hline & With someone & 408 & 78 \\
\hline & Missing & 7 & 1 \\
\hline \multicolumn{4}{|c|}{$\begin{array}{l}\text { Education past minimum } \\
\text { school-leaving age }\end{array}$} \\
\hline & Yes & 184 & 35 \\
\hline & No & 332 & 63 \\
\hline & Missing & 8 & 2 \\
\hline \multicolumn{4}{|c|}{ Employment status } \\
\hline & Retired & 275 & 52 \\
\hline & Employed & 141 & 27 \\
\hline & Un-employed & 104 & 20 \\
\hline & Missing & 4 & 1 \\
\hline \multicolumn{4}{|l|}{ Receive pension } \\
\hline & Yes & 328 & 63 \\
\hline & No & 191 & 36 \\
\hline & Missing & 5 & 1 \\
\hline
\end{tabular}


Table 4: Diabetes history of DMAS patients at baseline $(n=524)$

\begin{tabular}{|c|c|c|c|}
\hline & & Mean & $S D$ \\
\hline \multicolumn{2}{|l|}{ Years since diagnosis } & 10.2 & 7.6 \\
\hline & & $N$ & $\%$ \\
\hline \multicolumn{4}{|l|}{ Current Management } \\
\hline & No Medications & 2 & 1 \\
\hline & Oral hypoglycaemics only & 360 & 69 \\
\hline & Insulin only & 16 & 3 \\
\hline & $\begin{array}{l}\text { Insulin \& oral } \\
\text { hypoglycaemics }\end{array}$ & 134 & 25 \\
\hline & Missing & 12 & 2 \\
\hline \multicolumn{4}{|c|}{ Prior Diabetes Education } \\
\hline & Yes & 320 & 61 \\
\hline & No & 192 & 37 \\
\hline & Missing & 12 & 2 \\
\hline \multicolumn{4}{|c|}{ Monitoring blood glucose at home } \\
\hline & Yes & 461 & 88 \\
\hline & No & 59 & 11 \\
\hline & Missing & 4 & 1 \\
\hline \multicolumn{4}{|c|}{ Self-reported history of diabetes complications and co-morbidities } \\
\hline & High blood pressure & 369 & 70 \\
\hline & Stroke & 36 & 7 \\
\hline & Angina & 102 & 19 \\
\hline & Heart attack & 59 & 11 \\
\hline & High cholesterol & 311 & 59 \\
\hline & Eye problems & 128 & 24 \\
\hline & Kidney problems & 62 & 12 \\
\hline & Feet problems & 100 & 19 \\
\hline
\end{tabular}


Table 5: Medication adherence scores for DMAS participants at baseline and final visits Brief Medication Questionnaire (BMQ)

\begin{tabular}{|l|c|l|l|l|}
\hline & $\mathbf{n}$ & Baseline mean (Cl) & Final mean (CI) & Baseline versus final $\mathbf{p}$ value \\
\hline $\begin{array}{l}\text { Regimen screen \# } \\
\text { (range 0-8) }\end{array}$ & 346 & $1.2(1.08-1.34)$ & $0.84(0.73-0.95)$ & $<0.001$ \\
\hline $\begin{array}{l}\text { Belief screen * } \\
\text { (range 0-2) }\end{array}$ & 345 & $0.62(0.54-0.70)$ & $0.37(0.3-0.44)$ & $<0.0001$ \\
\hline $\begin{array}{l}\text { Recall screen } \\
\text { (range 0-2) }\end{array}$ & 347 & $0.98(0.92-1.04)$ & $1.00(0.93-1.06)$ & 0.58 \\
\hline $\begin{array}{l}\text { Total score } \\
\text { (range 0-12) }\end{array}$ & 338 & $2.80(2.61-3.00)$ & $2.20(2.03-2.38)$ & $<0.0001$ \\
\hline
\end{tabular}

\#Regimen screen - measures whether the patient knows the names, the purpose of all their medication(s) and how the patient has taken their medication(s) over the past 7 days

*Belief screen - measures whether patient believes the medication(s) are working and if they have experienced any problems with any medication

$\sim$ Recall screen - measures any problems the patients have with taking their medication(s) eg remembering, collecting refills, opening bottles etc 
Table 6: DDSMQ - Patient Satisfaction on Knowledge $(n=323)$

\begin{tabular}{|l|l|}
\hline & Degree of Satisfaction* \\
\hline $\begin{array}{l}\text { I am satisfied with my understanding of when I should check } \\
\text { my blood sugar levels }\end{array}$ & $97 \%$ strongly agree or agree \\
\hline $\begin{array}{l}\text { I am satisfied with my understanding of how things can } \\
\text { change my blood sugar levels because of diabetes }\end{array}$ & $91 \%$ strongly agree or agree \\
\hline $\begin{array}{l}\text { I am satisfied with my understanding of what I should eat to } \\
\text { control my diabetes }\end{array}$ & $93 \%$ strongly agree or agree \\
\hline $\begin{array}{l}\text { I am satisfied with my understanding of the types and } \\
\text { amounts of physical activity I can do to control my diabetes }\end{array}$ & $92 \%$ strongly agree or agree \\
\hline $\begin{array}{l}\text { I do not know what types of exercise are beneficial to control } \\
\text { my diabetes }\end{array}$ & $\begin{array}{l}73 \% \text { strongly disagree or } \\
\text { disagree }\end{array}$ \\
\hline
\end{tabular}

* For each item responses on the 5 point Likert scale were recoded into 3 categories and the highest proportion of responses is presented in the table 
Table 7: DDSMQ - Patient Satisfaction on Self-Management $(n=323)$

\begin{tabular}{|l|l|}
\hline & Degree of Satisfaction \\
\hline The service gave me confidence to deal with my diabetes & $89 \%$ strongly agree or agree \\
\hline $\begin{array}{l}\text { I am more compliant with my medications since participating } \\
\text { in the service }\end{array}$ & $81 \%$ strongly agree or agree \\
\hline I have improved my lifestyle since participating in the service & $76 \%$ strongly agree or agree \\
\hline $\begin{array}{l}\text { I feel a sense of accomplishment after achievement of my } \\
\text { goals and participating in the service }\end{array}$ & $83 \%$ strongly agree or agree \\
\hline The service motivated me to stay in control of my diabetes & $84 \%$ strongly agree or agree \\
\hline $\begin{array}{l}\text { I monitor my blood glucose levels before meals and at } \\
\text { bedtime on different days of the week since participating in } \\
\text { the service }\end{array}$ & $77 \%$ strongly agree or agree \\
\hline
\end{tabular}

* For each item responses on the 5 point Likert scale were recoded into 3 categories and the highest proportion of responses is presented in the table 
Figure 1: Percentage of patients* who received self-management support interventions (SMSIs)(n=524)

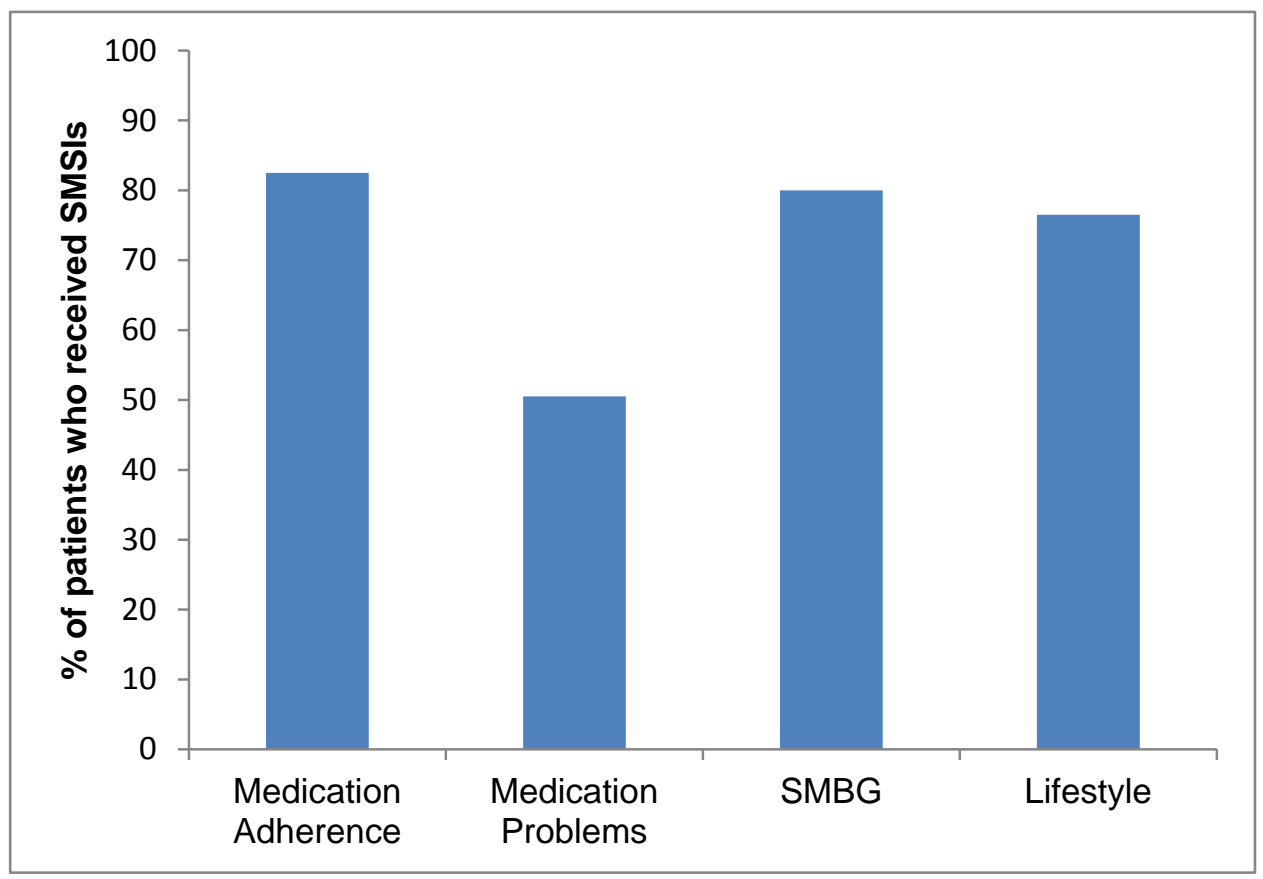

*Includes completed and non-completed patients 